\title{
Measurement of Fractional Exhaled Nitric Oxide: Comparison of Three Different Analysers
}

\author{
Stephanie Korn ${ }^{a}$ Maike Wilk ${ }^{a}$ Stefanie Voigt ${ }^{a}$ Stephan Weber ${ }^{b}$ \\ Thomas Keller $^{\mathrm{b}}$ Roland Buhl ${ }^{\mathrm{a}}$

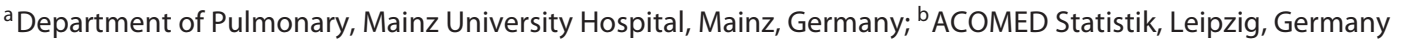

\section{Keywords}

Asthma $\cdot$ Nitric oxide $\cdot$ Inflammation · Airway markers

\begin{abstract}
Background: Fractional exhaled nitric oxide (FeNO) is a surrogate marker for airway inflammation, supporting the diagnostic pathway and treatment decisions for asthma patients. Objectives: Aim of this study was to compare the new analyser Vivatmo pro (Bosch, BV) with NIOX VERO (Circassia, CN) and CLD (Ecomedics, EC). Methods: In 100 asthmatics (median 53 years [range 20-87], 62\% female, $86 \%$ on inhaled corticosteroids [mean 1,300 $\mathrm{\mu g}$ beclomethasone dipropionate or equivalent], 35\% treated with biologics) 2 FeNO measurements per device were performed. Additionally, the success rate to achieve a valid NO value was evaluated. Results: Sixty-eight percent of the patients had FeNO values below 50 ppb. Median NO concentrations were 31 ppb (range 6-194) for BV, 33 ppb (9-164) for CN and 31 ppb (7-353) for EC. Bland-Altman plots suggested an agreement within the predefined limits of $\pm 5 \mathrm{ppb}$ for all analysers within the therapeutically relevant range (0-70 ppb). The highest agreement in FeNO levels were between BV and EC with mean differences of -0.26 ( $95 \% \mathrm{Cl}-1.48$ to 0.95$)$ vs. 1.52 (95\% Cl 0.4-2.6) $\mathrm{ppb}$ for $\mathrm{CN}$ and $\mathrm{EC}$. The results indicate an equivalence of the methods (two-one sided $t$ test-equivalence test: $p<0.0001$,
\end{abstract}

\pm 5 ppb margins). Acceptance of the measurements was high for all devices (97\%). The highest success rate to obtain 2 valid NO values without failed attempts was achieved with the BV analyser (73 vs. $62 \%$ for the CN analyser and $46 \%$ for the EC analyser). Conclusions: For the range between 0 and 70 ppb, FeNO concentrations measured with all 3 devices were statistically equivalent within predefined acceptance criteria and did not differ in a clinically relevant way.

(c) 2019 The Author(s)

Published by S. Karger AG, Basel

\section{Introduction}

Measurement of fractional exhaled nitric oxide(FeNO) is a quantitative, noninvasive, simple and safe method to assess Type 2-driven airway inflammation in respiratory diseases [1]. Type 2-driven airway inflammation is a hallmark of bronchial asthma, and several lines of evidence support the relationship between exhaled NO, IL-13 activity and eosinophilic inflammation in asthma [2, 3]. NO concentrations in the exhaled breath correlate well with Type 2 airway inflammation and is therefore recommended in international guidelines as an additional parameter supporting treatment decisions in symptomatic patients [4-10] In this regard, measurement of exhaled $\mathrm{NO}$ is useful to evaluate potential corticosteroid respon-

\begin{tabular}{ll}
\hline KARGER & $\begin{array}{l}\text { Karger } \\
\text { Published by S. Karger AG, Basel }\end{array}$ \\
E-Mail karger@karger.com & $\begin{array}{l}\text { This article is licensed under the Creative Commons Attribution- } \\
\text { NonCommercial-NoDerivatives 4.0 International License (CC BY- } \\
\text { NC-ND) (http://www.karger.com/Services/OpenAccessLicense). } \\
\text { Usage and distribution for commercial purposes as well as any dis- } \\
\text { tribution of modified material requires written permission. }\end{array}$
\end{tabular}


Table 1. Demographic-and asthma-relevant parameters of included patients

\begin{tabular}{|c|c|c|c|c|}
\hline Parameter & $n$ & $\%$ & Mean (SD) & Median (range) \\
\hline Women & 62 & 62.0 & & \\
\hline Age, years & 100 & & $51.3(14.0)$ & $53(20-87)$ \\
\hline Height, cm & & & $170.8(8.9)$ & $170.5(154-193)$ \\
\hline Asthma diagnosis, years & & & $21.9(14.0)$ & $20(0-62)$ \\
\hline Weight, kg & & & $80.2(18.6)$ & $78.5(43-147)$ \\
\hline BMI, $\mathrm{kg} / \mathrm{m}^{2}$ & & & $27.4(6.0)$ & $26.1(16.8-53.3)$ \\
\hline FEV1, L & & & $2.2(0.9)$ & $2.2(0.7-5.5)$ \\
\hline FEV1, \% & & & $71.4(23.1)$ & $75.0(23-131)$ \\
\hline FVC, L & & & $3.2(1.0)$ & $3.1(1.2-6.5)$ \\
\hline FVC, \% & & & $86.7(20.7)$ & $86.5(39-139)$ \\
\hline $\mathrm{ACT}$ & & & $16(5.7)$ & $15(5-25)$ \\
\hline Allergy sufferers & 68 & 68.0 & & \\
\hline Former smokers & 45 & 45.0 & & \\
\hline Pack-years & & & $8.4(9.5)$ & $6.5(1-60)$ \\
\hline \multicolumn{5}{|l|}{ Medication } \\
\hline ICS dose, $\mu \mathrm{g}$ BDP/day & 86 & 86.0 & $1,314(842)$ & $1,000(200-4,000)$ \\
\hline LABA & 75 & 75.0 & & \\
\hline LAMA & 41 & 41.0 & & \\
\hline Biologicals* & 35 & 35.0 & & \\
\hline
\end{tabular}

siveness, or conversely, helping to identify poor corticosteroid compliance $[11,12]$. Elevated levels of NO in asthmatic patients have been shown to correlate with disease activity, and more importantly, with subsequent deterioration in asthma control $[13,14]$. FeNO even predicts the response to inhaled corticosteroids in patients with nonspecific respiratory symptoms [15]. The FeNO measurement is easy to perform, reproducible, associated with a high degree of acceptance by patients and thus a useful marker for asthma patients in primary care [16]. Furthermore, in the current NICE clinical guideline on asthma, FeNO is recommended for the management of patients who remain symptomatic on inhaled corticosteroids [7]. The introduction of FeNO testing in primary care settings can be achieved with a very low effort with respect to measurement procedures and data interpretation, while simultaneously improving the quality of care $[7,17]$.

FeNO can be measured using several commercially available analysers which differ in some aspects, for example, methods of measurements, complexity or set-up [18]. Stationary analysers usually measure FeNO by chemiluminescent techniques, whilst handheld devices measure FeNO using electrochemistry. Independent of the measurement technology and in order to assure reliable measurements the analysers follow the standardized measurement procedures recommended by ATS (American Thoracic Society) and ERS (European Respiratory Society) [19].

As yet there is limited data on whether the results of the different analyzers are comparable. For clinical practice it is important to know whether the instruments used to measure exhaled NO can be used interchangeably [20].

Consequently, the aim of this study was to compare the newly available handheld $\mathrm{FeNO}$ analyser Vivatmo pro (BV; Bosch Healthcare Solutions, Waiblingen, Germany) in clinical routine with 2 reference devices: another handheld FeNO analyser NIOX VERO ${ }^{\circledR}(\mathrm{CN}$; Circassia Pharmaceuticals plc, Oxford, United Kingdom) and the stationary Ecomedics analyser CLD 88 (EC; Eco Medics AG, Duernten, Switzerland).

\section{Methods}

\section{Subjects}

From November 28, 2017 to February 02, 2018 a total of 106 asthma patients were invited to participate in the study (Table 1), all of whom had to be non-smokers for at least 1 year. Patients with a respiratory tract infection were excluded. The study was per- 
formed according to Good Clinical Practice standards and the Declaration of Helsinki, and was approved by the local Ethics Committee. All participants gave a written informed consent.

Nitric Oxide Analysers

According to the manufacturers, both handheld devices Vivatmo pro $(\mathrm{BV})$ and NIOX VERO $(\mathrm{CN})$ were precalibrated during the production and are service- and calibration-free systems. The BV device is further maintenance-free and does not require any exchange of the internal Chemical Field Effect (ChemFET) sensor. The CLD 88 (EC) was calibrated using calibration gas containing 3 parts per million (ppm) of $\mathrm{NO}$ in $\mathrm{N}_{2}$ monthly ( $\mathrm{NO}$ calibration), and each day the flow measurement (flow calibration) and NO zero was calibrated as recommended by the manufacturer.

\section{Exhaled Nitric Oxide Measurements}

Exhaled NO measurements were performed according to the consensus guideline of the ERS and the ATS [18]. As exhaled NO values are highly flow dependent, all measurements were performed at a standardized exhalation flow rate of $50 \mathrm{~mL} / \mathrm{s}$. Patients had to exhale against a positive counter pressure of $10 \mathrm{~cm} \mathrm{H}_{2} \mathrm{O}$ to avoid cross-contamination with nasal NO. In order to guide the subjects in performing a valid exhalation manoeuvre, the flow parameters were controlled by visible and/or audible feedback.

Patients performed 2 consecutive measurements on each analyser with a random pre-defined measuring sequence concerning device order. In line with current guidelines 2 min relaxed tidal breathing between measurements were observed to avoid the potential confounding effect of serial inhalation/exhalation manoeuvres, which may lead to a decline in measured exhaled $\mathrm{NO}$ values $[15,18]$. Exhaled NO levels were automatically calculated by the analysers and represented the mean of 2 technically adequate and reproducible measurements [14]. According to the manufacturers' instrument manuals the measurement ranges of the devices were 5-300 ppb for the BV device and the $\mathrm{CN}$ device, and 0.1-5,000 ppb for the EC device.

All measurements were completed within $1 \mathrm{~h}$ on the same day. After the measurements patients evaluated the different devices. They were asked to rate the analysers overall according to comfort and ease of performing the measurement. After measurement of exhaled NO, spirometry was performed in accordance with the ATS guidelines [19].

Ambient $\mathrm{NO}$ values were recorded for each patient prior to exhaled NO measurements using the value automatically obtained by the CLD 88 analyser.

\section{Statistical Analyses}

Descriptive data included means $( \pm S D)$ or medians and quartiles for continuous end-points (e.g., $\mathrm{NO}$ values), and frequencies for categorical end-points (NO values $\langle/\rangle=40 \mathrm{ppb}$, patient characteristics and patient evaluation of the analysers).

The primary objective of the study was to estimate the bias and to show equivalence between the analysers BV, EC and CN. According CLSI-EP09-A3 guidance difference plots as well as a specific regression method (Passing-Bablok regression) were applied to estimate the difference (primary endpoint) and the slope/intercept, respectively [21-23]. The analyses focussed on the main therapeutical relevant level up to $70 \mathrm{ppb}$, and on the area in which the cutpoints for a positive test or the presence of significant Type- 2 inflammation are located [6]. Using the equivalence testing frame- work equivalence is demonstrated when the CI (here 90\%) of the difference between the methods is within predefined limits $( \pm 5 \mathrm{ppb}$ in the range $0-70 \mathrm{ppb}, \pm 10 \%$ in the range $>70 \mathrm{ppb}$ ). The corresponding $p$ values were obtained with the two-one sided $t$ test (TOST) [24]. The limits of agreement were calculated as the (95\%, 95\%)-tolerance interval of the mean of the differences [25]. Using the currently proposed clinical decision limit, binary measures $(</ \geq 40 \mathrm{ppb})$ were introduced and agreement of the methods was evaluated (positive and negative percent agreement, overall agreement) [7]. Repeatability was calculated as intraserial precision estimated by random effects ANOVA following the CLSI EP05-A3 guidance [26].

Further endpoints were evaluation of success rates and number of attempts needed by each of the devices.

All patients with valid measurement results of all 3 methods were included in the analysis.

A sample size calculation applying TOST within difference plot used the following assumptions: alpha level of $5 \%$, power of $80 \%$, a real difference of $3 \mathrm{ppb}$ (for NO-values $>50 \mathrm{ppb} 2 \%$ ) with a SD of $5 \mathrm{ppb}(15 \%)$, and a proportion of patients with missing results of $5 \%$. It resulted in 106 cases to be included.

Data analysis was performed using software SAS 9.4 (SAS Institute, Cary, NC, USA).

\section{Results}

In the study valid results for 100 patients from all 3 devices were obtained. Six patients did not accomplish 2 valid measurement values from all 3 devices, due to a FeNO level above the measurement range of the handheld devices $(n=1)$, technical problems $(n=2)$ or because they were not able to perform measurements with all the devices $(n=3)$.

In $68 \%$ of patients FeNO values were below $50 \mathrm{ppb}$, $89 \%$ had FeNO values up to $70 \mathrm{ppb}$ as measured by EC. Median NO concentrations were 31 ppb (range 6-194) for BV, 33 ppb (9-147) for CN and 31 ppb (7-167) for EC.

Bland-Altman plots showed a high agreement (and equivalence within the statistical equivalence testing framework) in absolute FeNO levels for individual patients as well as an agreement within the predefined maximum bias of $\pm 5 \mathrm{ppb}$ obtained with all analysers within the therapeutically relevant range of $0-70 \mathrm{ppb}$ between BV vs. EC and BV vs. CN (Fig. 1).

Agreement in absolute FeNO levels for individual patients was evaluated for pairwise analysers' comparisons, with mean differences of $-0.26 \mathrm{ppb}$ ( $90 \% \mathrm{CI}-1.48$ to 0.95 ; TOST $p$ value $<0.0001$ ) between BV and EC analysers, -1.78 (90\% CI -3.11 to -0.45 ; TOST $p$ value $<0.0001)$ for BV vs. $\mathrm{CN}$ and 1.52 (90\% CI 0.43-2.60; TOST $p$ value $<0.0001)$ between $\mathrm{CN}$ and EC. The results suggested that FeNO values obtained with the $\mathrm{CN}$ were generally slightly higher than the FeNO measurements obtained with BV and EC. 


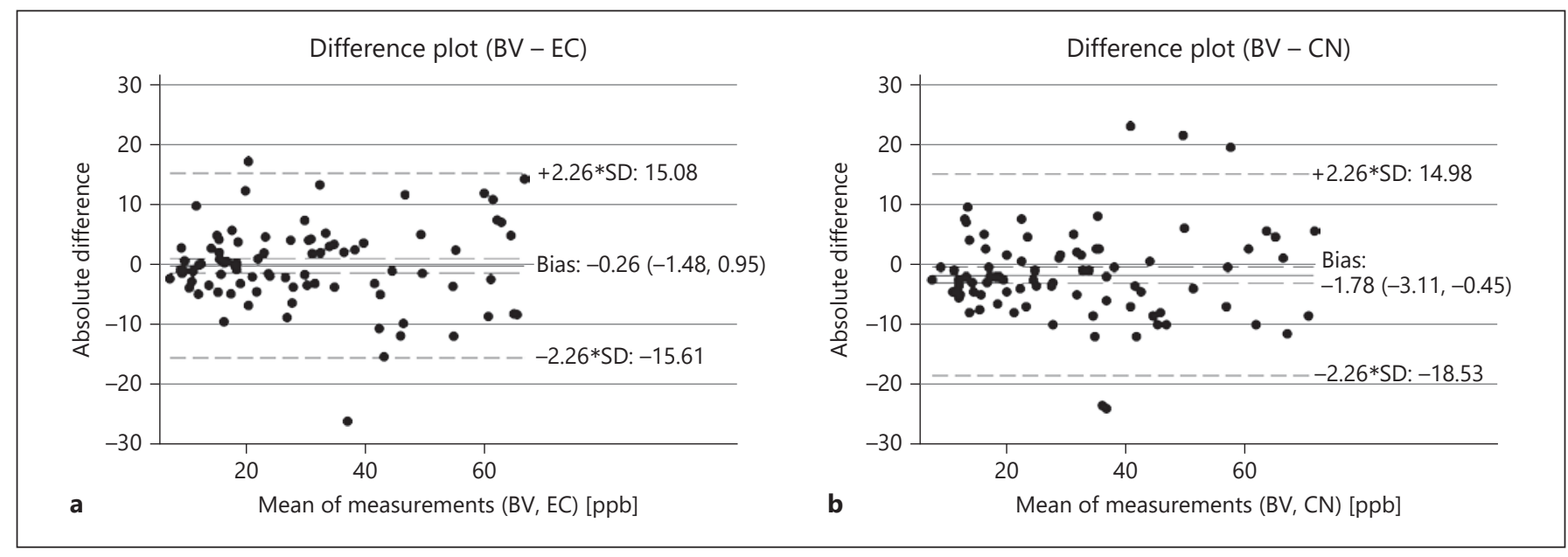

Fig. 1. Bland-Altman difference plot for absolute differences (range 0-70 ppb) of the mean of 2 valid FeNO measurements using the BV vs. EC (a) and the BV vs. CN (b).

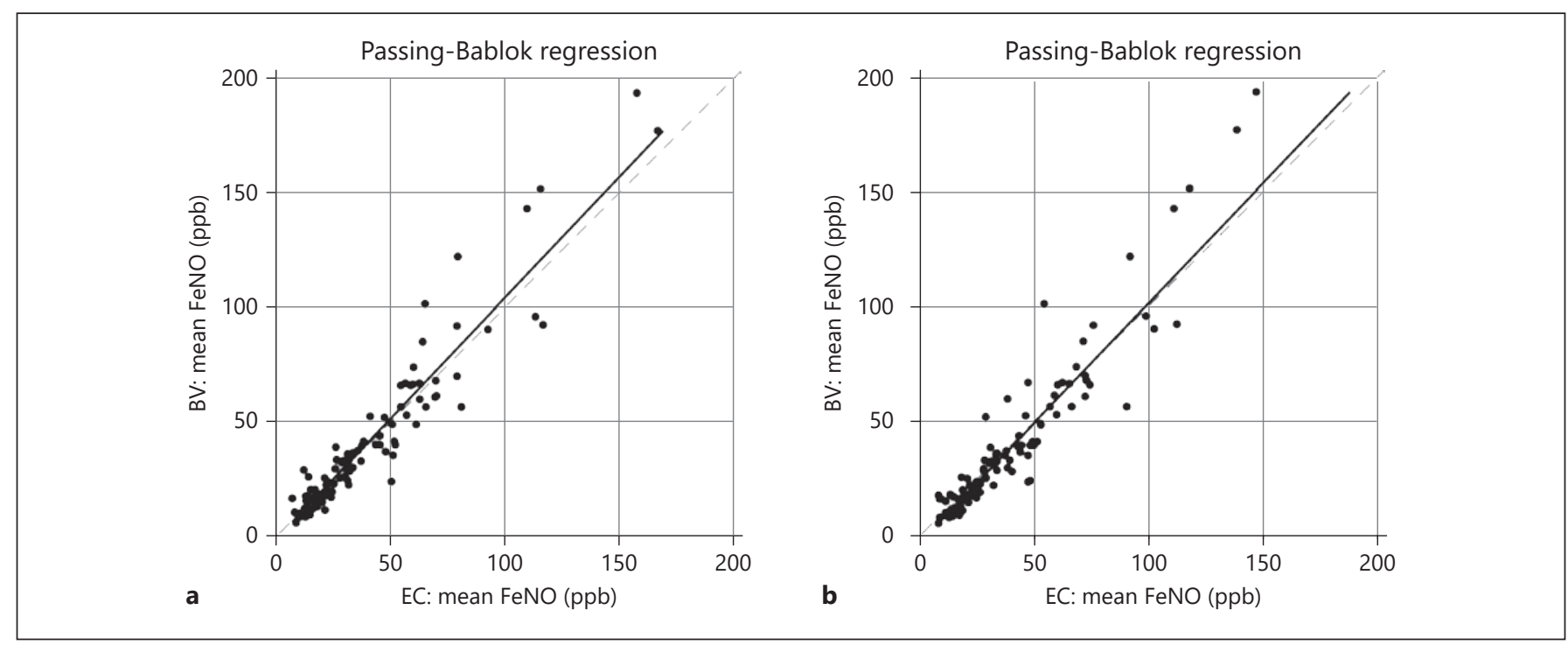

Fig. 2. Device agreement: Passing-Bablok regression with scatter plots of the mean of 2 valid FeNO measurements using the BV vs. EC (a) and the BV vs. CN (b; Dashed line: Identity, Solid line: Passing-Bablok regression line). FeNO, fractional exhaled nitric oxide.

For patients with a higher intensity of airway inflammation and for those who needed $>3$ attempts per device, the variation of the FeNO measurements both within a single device and between different analysers was higher. Thus, for patients with FeNO values above $70 \mathrm{ppb}$ the mean inter-device bias was $8.6 \%$ (90\% CI -3.1 to $20.2 \%$; TOST $p$ value 0.4159$)$ for BV vs. EC, $9.6 \%$ (90\% CI -2.9 to $22.1 \%$; TOST $p$ value 0.4782 ) for $\mathrm{BV}$ vs. $\mathrm{CN}$, and $-1.1 \%$ (90\% CI -6.3 to $4.2 \%$; TOST $p$ value 0.0047 ) for $\mathrm{CN}$ vs. EC (Fig. 1).
Difference plot analysis for the differences between 2 devices (range $<70 \mathrm{ppb}$ ) showed a mean inter-device bias of $0.21 \mathrm{ppb}$ ( $90 \%$ CI -1.16 to 1.58 ; TOST $p$ value $<0.0001$ ) between BV and EC compared to $1.15 \mathrm{ppb}$ ( $90 \% \mathrm{CI}-0.14$ to 2.45; TOST $p$ value $<0.0001$ ) for $\mathrm{CN}$ and $\mathrm{EC}$ in the case that only the first measurements were considered.

The calculated Passing-Bablok-regression coefficients indicate a good agreement of FeNO levels between BV vs. EC and BV vs. CN (Fig. 2), with slopes of 1.054 (95\% CI $0.96-1.15)$ and 1.045 (95\% CI 0.96-1.15), and intercepts 
of -1.12 (95\% CI -3.09 to 0.66$)$ and -3.09 (95\% CI -5.93 to -1.23 ) respectively. Results indicate a statistically significant constant offset for BV vs. CN (as the CI for intercept does not include zero); however, as the visual inspection of the scatterplot indicates, this might be primarily related to observed differences between analysers in the $>70 \mathrm{ppb}$ range.

Repeatability coefficients within the therapeutically relevant range (ICCs, random effects ANOVA) were 0.944 (SD $4.2 \mathrm{ppb}$ ) for BV and 0.946 (SD $4.1 \mathrm{ppb}$ ) for CN. Thus, both handheld devices showed a comparable high repeatability.

Based on the NICE classification, a FeNO measurement of $\geq 40 \mathrm{ppb}$ or higher is rated as a positive FeNO testing [14]. The overall percentage agreement (OPA) between the different analyzers within this predefined clinical cutoff was high: $96 \%$ of patients with the BV and $94 \%$ with the CN were classified equally as FeNO positive or negative compared to the measurement with the EC (Tables 2-4). Positive and negative percentage agreement (PPA/NPA) were 98.4/92.1\% for BV vs. EC and $93.5 / 94.7 \%$ for $\mathrm{CN}$ vs. EC respectively. For BV compared to $\mathrm{CN}$ the result was $92 \%$ in terms of OPA and $96.7 / 85.0 \%$ in terms of PPA/NPA.

According to the ATS classification, FeNO levels above $50 \mathrm{ppb}$ likely indicate significant airway inflammation [6]. Considering this cutoff for clinically relevant inflammation, the OPA of BV and CN compared to EC were 92\% (PPA 81.3\%; NPA 97.1\%) and 95\% (PPA 84.4\%; NPA $100 \%$ ), respectively, and 93\% (PPA $88.9 \%$; NPA 94.5\%) for BV vs. CN.

The ambient NO levels recorded in this study ranged between 4 and $139 \mathrm{ppb}$ (mean $47 \pm 27 \mathrm{ppb}$ ).

To evaluate a potential impact of ambient $\mathrm{NO}$ on the measurements with the handheld devices, the interfering ambient $\mathrm{NO}$ was correlated with the absolute differences of the FeNO readings of the handheld devices (BV and $\mathrm{CN}$ ) toward the EC measurements. Ambient NO levels showed a significant linear correlation with higher FeNO readings for both handheld devices (BV and $\mathrm{CN}$ ) compared to the EC measurements $(p<0.05)$; however, the correlation was only moderate (Pearson $r<0.5$ ). The mean of absolute differences for both handheld devices was within the specific accuracy of $\pm 5 \mathrm{ppb}$. Accordingly, no clinically relevant effect of ambient $\mathrm{NO}$ on FeNO was detected.

In this study set-up, no other asthma-related co-factor such as years since diagnosis, asthma control, asthma severity, FEV1, medication, allergic status, or BMI had a significant influence on FeNO differences between the analyzers.

FeNO Measured with Different Analysers
Table 2. Agreement of FeNO results with the tested devices based on NICE criteria for a positive FeNO test ( $\geq 40 \mathrm{ppb}$ assumed as a positive test result); overall agreement for $\mathrm{BV}$ vs. EC

\begin{tabular}{lccc}
\hline FeNO & \multicolumn{2}{l}{ EC } & Total \\
\cline { 2 - 3 } & $<40 \mathrm{ppb}$ & $\geq 40 \mathrm{ppb}$ & \\
\hline $\mathrm{BV}$ & & & \\
$<40 \mathrm{ppb}$ & 61 & 3 & 64 \\
$\geq 40 \mathrm{ppb}$ & 1 & 35 & 36 \\
\hline Total & 62 & 38 & 100 \\
\hline
\end{tabular}

Overall agreement for BV vs. EC: 96/100 = 96\% (95\% CI 90.198.9\%). Positive percent agreement: $35 / 38=92.1 \%$ (95\% CI 78.6$98.3 \%$ ). Negative percent agreement: $61 / 62=98.4 \%$ (95\% CI $91.3-$ $100.0 \%)$

FeNO, fractional exhaled nitric oxide.

Table 3. Agreement of FeNO results with the tested devices based on NICE criteria for a positive FeNO test ( $\geq 40 \mathrm{ppb}$ assumed as a positive test result); overall agreement for $\mathrm{BV}$ vs. $\mathrm{CN}$

\begin{tabular}{lccc}
\hline FeNO & \multicolumn{2}{c}{ CN } & Total \\
\cline { 2 - 3 } & $<40 \mathrm{ppb}$ & $\geq 40 \mathrm{ppb}$ & \\
\hline $\mathrm{BV}$ & & & \\
$<40 \mathrm{ppb}$ & 58 & 6 & 64 \\
$\geq 40 \mathrm{ppb}$ & 2 & 34 & 36 \\
\hline Total & 60 & 40 & 100 \\
\hline
\end{tabular}

Overall agreement for BV vs. CN: 92/100 = 92\% (95\% CI 84.896.5\%). Positive percent agreement: $34 / 40=85.0 \%$ (95\% CI $70.2-$ $94.3 \%)$. Negative percent agreement: $58 / 60=96.7 \%$ (95\% CI $88.5-$ 99.6\%).

FeNO, fractional exhaled nitric oxide.

Table 4. Agreement of FeNO results with the tested devices based on NICE criteria for a positive FeNO test ( $\geq 40 \mathrm{ppb}$ assumed as a positive test result); overall agreement for $\mathrm{CN}$ vs. EC

\begin{tabular}{lccc}
\hline FeNO & \multicolumn{2}{l}{ EC } & Total \\
\cline { 2 - 3 } & $<40 \mathrm{ppb}$ & $\geq 40 \mathrm{ppb}$ & \\
\hline $\mathrm{CN}$ & 58 & 2 & \\
$<40 \mathrm{ppb}$ & 4 & 36 & 60 \\
$\geq 40 \mathrm{ppb}$ & 62 & 38 & 40 \\
\hline Total & 62 & 100 \\
\hline
\end{tabular}

Overall agreement for CN vs. EC: $94 / 100=94 \%$ (95\% CI $87.4-$ 97.8\%). Positive percent agreement: $36 / 38=94.7 \%$ (95\% CI $82.3-$ $99.4 \%$ ). Negative percent agreement: $58 / 62=93.5 \%$ (95\% CI $84.3-$ 98.2\%).

FeNO, fractional exhaled nitric oxide. 
In general, the acceptance of FeNO measurements was high among the patients independently of the device. Among all devices, $97 \%$ of all patients rated the FeNO measurement as pleasant to very pleasant compared to spirometry and approximately $90 \%$ of all patients valued the measurement as easy to very easy. Seventy percent of the patients already had experience with FeNO measurements and 65\% already knew the $\mathrm{CN}$ analyzer.

The highest success rate to achieve 2 valid NO values without failed attempts was achieved with the BV analyser for $73 \%$ of patients vs. $62 \%$ for the $\mathrm{CN}$ analyser and $46 \%$ for the EC analyser. However, within up to 3 attempts in over $80 \%$ of the participants, 2 successful measured values were achieved for all devices $(\mathrm{BV}=86 \%$, $\mathrm{CN}=85 \%, \mathrm{EC}=81 \%)$.

\section{Discussion}

The present study evaluated the equivalence to measure FeNO in asthma patients between the recently introduced $\mathrm{BV}$ and $\mathrm{CN}$ as another common handheld device and the stationary device EC as the reference method. It confirmed equivalence of the BV device with the other devices within the predefined limit $( \pm 5 \mathrm{ppb})$ in the range of 0-70 ppb.

Previous comparisons between different devices for measuring exhaled NO gave inconsistent results [27-30]. The Bland-Altman-plots of the present study indicate an acceptable degree of agreement between the 3 analysers for patients with a FeNO in the range of $0-70 \mathrm{ppb}$. However, FeNO values obtained with the $\mathrm{CN}$ were slightly higher than with the EC or BV. In addition, in patients with higher FeNO values ( $>70 \mathrm{ppb}$ ) the variation of FeNO between all analyser was increased and the BV device seems to result in higher FeNO readings than both the EC and the $\mathrm{CN}$ devices. However, in the area above $70 \mathrm{ppb}$, only a very limited number of measurement results have been determined.

The clinical implication of these findings is that in patients with FeNO values $<70 \mathrm{ppb}$, the exhaled NO concentrations measured with all 3 devices were statistically equivalent within predefined acceptance criteria and, thus, are compatible. This information is of relevance, since quite often clinical decisions have to be based on FeNO values obtained with different devices. This is true even though in patients with high FeNO concentrations $(>70 \mathrm{ppb})$ where the spread increases with repeated measurements and with the use of different analyzers. Consequently, measurements of individual patients with high values should be assessed with caution. On the other hand, the clinical significance of very high FeNO values and differences between high values is limited. In the case of FeNO concentrations above $50 \mathrm{ppb}$, only a change above $20 \%$ is considered a clinically relevant trend [6]. Data on the course of therapy for this patient population with FeNO values above $70 \mathrm{ppb}$ are hardly available, and therefore long-term studies with a higher FeNO measurement frequency (daily to weekly) would be useful to better evaluate the clinical relevance of changes in in this high range.

The results from the present study confirm those from earlier smaller trials. First, there was a good correlation between results obtained with the $\mathrm{CN}$ and EC devices [28-30], even though there was a consistent bias toward slightly higher readings in the order of 1-2 ppb when the EC as compared with the CN [29, 30]. Alving et al. [29] suggested that between-analyser differences were due to the use of different calibration gases and/or measurement procedures. In the present study, the calibration of the EC was performed according to the manufacturer's instructions and the $\mathrm{CN}$ and $\mathrm{BV}$ were precalibrated by the manufacturer.

Previous studies addressed the impact of ambient NO on FeNO measurements for chemiluminescent- and electrochemistry-based measurement techniques. Some of these studies reported that exhaled NO was influenced by ambient NO [31, 32], whereas others reported no effect of ambient $\mathrm{NO}$ on FeNO values $[33,34]$. Elevated ambient NO concentrations lead to an increased NO peak during the initial phase of the breath maneuver; however, the height of the resulting NO plateau is unaffected of the ambient NO concentration $[33,35]$. Some of the commercially available NO analysers, use a 2 -step breath manoeuvre to reduce this effect, which consists of an inhalation step with NO-free air prior to the exhalation step. Alternatively, an interference with ambient $\mathrm{NO}$ can also be avoided by a one-step breath manoeuvre based on an optimized dead space in the measuring system to allow an effective bypass of the increased NO peak. This is the underlying approach of the gas flow technology within the $\mathrm{BV}$ analyser in combination with the corresponding mouthpiece.

The results show that even high levels of ambient $\mathrm{NO}$ in the environment have no clinical relevant interference on the FeNO measurements in the devices tested.

Additionally, in this study set-up, no other factors introducing measurement differences between the devices were detected. The majority of patients had already used 
different devices for FeNO measurement in the past and $65 \%$ of the patients previously used $\mathrm{CN}$. However, the highest success rate was achieved with the newly launched BV. This indicates its easy and intuitive usage for patients with asthma. Because of its small size and portability, the $\mathrm{BV}$ can be expected to be used more generally and effectively, both in clinical practice and in research studies.

The ATS/ERS guidelines recommend a dual measurement of FeNO to obtain a valid value. The results of the present study indicate that a single measurement using the $\mathrm{BV}$ also led to valid FeNO values. This is in line with findings by Horváth et al. [36] suggesting the use of handheld devices in the case that just one measurement can be performed due to financial or other constraints.

Many easy-to-use NO analysers are now available. This may allow information regarding the underlying airway inflammation to be increasingly used in asthma management, particularly in the primary care setting. Further studies will have to answer the important question whether all the instruments used to measure exhaled NO accurately reflect disease activity, and when measurements change, whether this is because a different device has been used.

Potential limitations of this study include the necessity to perform serial inhalation/exhalation manoeuvres, which may lead to a decline in measured exhaled NO values [15]. Consequently, and in line with current guidelines, 2 min relaxed tidal breathing between measurements avoided the potential confounding effect [18]. This is true even though in patients with high FeNO concentrations ( $>70 \mathrm{ppb})$, the spread of repeated measurements and within the different analyzers increased. The number of patients with high FeNO concentrations was too small to evaluate the equivalence of the different devices. A further limitation is that this study only involved adult patients and no children.

In summary, the present study confirms that absolute exhaled NO measurements do not vary in a clinically relevant way between the $\mathrm{BV}, \mathrm{EC}$, and $\mathrm{CN}$ devices in patients with FeNO values in the range of $0-70 \mathrm{ppb}$. Consequently, the BV may be as effective as stationary chemiluminescence $\mathrm{NO}$ analyzers when used in clinical practice.

\section{Statement of Ethics}

This study was approved by the Research Ethical Committee of Universitätsmedizin Mainz. This study was supported by Bosch Healthcare Solutions GmbH.

\section{Disclosure Statement}

S.K. has received a grant by Bosch Healthcare Solutions GmbH for the participation at a pulmonary congress. M.W., S.V., and R.B. have no conflicts of interest.

\section{Author Contributions}

All authors contributed to the conception and design of the study, drafted the article, revised it critically, and finally approved of this submitted version.

\section{References}

1 Pijnenburg MW, De Jongste JC. Exhaled nitric oxide in childhood asthma: a review. Clin Exp Allergy. 2008 Feb;38(2):246-59.

2 Bousquet J, Chanez P, Lacoste JY, Barnéon G, Ghavanian N, Enander I, et al. Eosinophilic inflammation in asthma. N Engl J Med. 1990 Oct;323(15):1033-9.

3 Taylor DR. Nitric oxide as a clinical guide for asthma management. J Allergy Clin Immunol. 2006 Feb;117(2):259-62.

4 Berry MA, Shaw DE, Green RH, Brightling CE, Wardlaw AJ, Pavord ID. The use of exhaled nitric oxide concentration to identify eosinophilic airway inflammation: an observational study in adults with asthma. Clin Exp Allergy. 2005 Sep;35(9):1175-9.

5 Malmberg LP, Turpeinen H, Rytilä P, Sarna S, Haahtela T. Determinants of increased exhaled nitric oxide in patients with suspected asthma. Allergy. 2005 Apr;60(4):464-8.
6 Dweik RA, Boggs PB, Erzurum SC, Irvin CG, Leigh MW, Lundberg JO, et al.; American Thoracic Society Committee on Interpretation of Exhaled Nitric Oxide Levels (FENO) for Clinical Applications. An official ATS clinical practice guideline: interpretation of exhaled nitric oxide levels (FENO) for clinical applications. Am J Respir Crit Care Med. 2011 Sep;184(5):60215.

7 National Institute for Health and Care Excellence. Asthma: diagnosis, monitoring and chronic asthma management. London: NICE; NICE guideline 80; 2017. https://www.nice. org.uk/guidance/ng80/resources/asthma-diagnosis-monitoring-and-chronic-asthmamanagement-pdf-1837687975621 (citated July 25, 2018).

8 Buhl R, Bals R, Baur X, Berdel D, Criée CP Gappa M, et al.; Deutsche Gesellschaft für Ar- beitsmedizin und Umweltmedizin e.V.; Deutsche Gesellschaft für Rehabilitationswissenschaften e.V.; und Deutsche Gesellschaft für Gynäkologie und Geburtshilfe e.V. [Guideline for the Diagnosis and Treatment of Asthma - Guideline of the German Respiratory Society and the German Atemwegsliga in Cooperation with the Paediatric Respiratory Society and the Austrian Society of Pneumology]. Pneumologie. 2017 Dec;71(12): 849-919.

9 Wang Z, Pianosi P, Keogh K, Zaiem F, Alsawas M, Alahdab F, et al. The Clinical Utility of Fractional Exhaled Nitric Oxide (FeNO) in Asthma Management. Rockville, Agency for Healthcare Research and Quality; 2017. Comparative Effectiveness Review No. 197. https://www.effectivehealthcare. ahrq.gov/reports/final.cfm (citated July 25, 2018). 
10 Global Initiative for Asthma. Global strategy for asthma management and Prevention, 2018. 2018 GINA Report. www.ginasthma. org (citated July 25, 2018)

11 Pijnenburg MW, Bakker EM, Hop WC, De Jongste JC. Titrating steroids on exhaled nitric oxide in children with asthma: a randomized controlled trial. Am J Respir Crit Care Med. 2005 Oct;172(7):831-6.

12 Smith AD, Cowan JO, Brassett KP, Herbison GP, Taylor DR. Use of exhaled nitric oxide measurements to guide treatment in chronic asthma. N Engl J Med. 2005 May;352(21): 2163-73.

13 Jatakanon A, Lim S, Kharitonov SA, Chung KF, Barnes PJ. Correlation between exhaled nitric oxide, sputum eosinophils, and methacholine responsiveness in patients with mild asthma. Thorax. 1998 Feb;53(2): 91-5.

14 Strunk RC, Szefler SJ, Phillips BR, Zeiger RS, Chinchilli VM, Larsen G, et al.; Childhood Asthma Research and Education Network of the National Heart, Lung, and Blood Institute. Relationship of exhaled nitric oxide to clinical and inflammatory markers of persistent asthma in children. J Allergy Clin Immunol. 2003 Nov;112(5):883-92.

15 Price DB, Buhl R, Chan A, Freeman D, Gardener E, Godley C, et al. Fractional exhaled nitric oxide as a predictor of response to inhaled corticosteroids in patients with nonspecific respiratory symptoms and insignificant bronchodilator reversibility: a randomised controlled trial. Lancet Respir Med. 2018 Jan;6(1):29-39.

16 Kharitonov SA, Gonio F, Kelly C, Meah S, Barnes PJ. Reproducibility of exhaled nitric oxide measurements in healthy and asthmatic adults and children. Eur Respir J. 2003 Mar; 21(3):433-8.

17 National Institute for Health and Care Excellence. Asthma: diagnosis and monitoring guideline. Primary care implementation feasibility project. London: NICE; NICE guideline 80. Appendix Q: Feasibility report. 2017; pp 835-68. https://www.nice.org.uk/guid- ance/ng $80 /$ evidence/appendices-a-rpdf-4656178048 [citated July 25, 2018].

18 Müller KC, Jörres RA, Magnussen H, Holz O. Comparison of exhaled nitric oxide analysers. Respir Med. 2005 May;99(5):631-7.

19 American Thoracic SocietyEuropean Respiratory Society. ATS/ERS recommendations for standardized procedures for the online and offline measurement of exhaled lower respiratory nitric oxide and nasal nitric oxide, 2005. Am J Respir Crit Care Med. 2005 Apr; 171(8):912-30.

20 Korn S, Telke I, Kornmann O, Buhl R. Measurement of exhaled nitric oxide: comparison of different analysers. Respirology. 2010 Nov; 15(8):1203-8.

22 Bland JM, Altman DG. Statistical methods for assessing agreement between two methods of clinical measurement. Lancet. 1986 Feb; 1(8476):307-10.

23 Passing $\mathrm{H}, \mathrm{Bablok} \mathrm{W}$. A new biometrical procedure for testing the equality of measurements from two different analytical methods. Application of linear regression procedures for method comparison studies in clinical chemistry, Part I. J Clin Chem Clin Biochem. 1983 Nov;21(11):709-20.

24 Schuirmann DJ. A comparison of the two one-sided tests procedure and the power approach for assessing the equivalence of average bioavailability. J Pharmacokinet Biopharm. 1987 Dec;15(6):657-80.

25 Barnhart HX, Haber MJ, Lin LI. An overview on assessing agreement with continuous measurements. J Biopharm Stat. 2007;17(4):52969.

26 Clinical and Laboratory Standards Institute. Evaluation of Precision of Quantitative Measurement Procedures. Approved Guideline Third Edition. CLSI document EP05-A3. Wayne, Clinical and Laboratory Standards Insititute; 2014

27 Borrill Z, Clough D, Truman N, Morris J, Langley S, Singh D. A comparison of exhaled nitric oxide measurements performed using three different analysers. Respir Med. 2006 Aug;100(8):1392-6.
28 Boot JD, de Ridder L, de Kam ML, Calderon C, Mascelli MA, Diamant Z. Comparison of exhaled nitric oxide measurements between NIOX MINO electrochemical and Ecomedics chemiluminescence analyzer. Respir Med. 2008 Nov; 102(11):1667-71.

29 Alving K, Janson C, Nordvall L. Performance of a new hand-held device for exhaled nitric oxide measurement in adults and children. Respir Res. 2006 Apr;7(1):67.

30 Menzies D, Nair A, Lipworth BJ. Portable exhaled nitric oxide measurement: comparison with the "gold standard" technique. Chest. 2007 Feb;131(2):410-4.

31 Byrnes CA, Dinarevic S, Busst CA, Shinebourne EA, Bush A. Effect of measurement conditions on measured levels of peak exhaled nitric oxide. Thorax. 1997 Aug;52(8): 697-701.

32 Baraldi E, Azzolin NM, Dario C, Carra S, Ongaro R, Biban P, et al. Effect of atmospheric nitric oxide $(\mathrm{NO})$ on measurements of exhaled NO in asthmatic children. Pediatr Pulmonol. 1998 Jul;26(1):30-4.

33 Silkoff PE, McClean PA, Slutsky AS, Furlott HG, Hoffstein E, Wakita S, et al. Marked flowdependence of exhaled nitric oxide using a new technique to exclude nasal nitric oxide. Am J Respir Crit Care Med. 1997 Jan;155(1):260-7.

34 Piacentini GL, Bodini A, Vino L, Zanolla L, Costella S, Vicentini L, et al. Influence of environmental concentrations of $\mathrm{NO}$ on the exhaled NO test. Am J Respir Crit Care Med. 1998 Oct;158(4):1299-301.

35 Recommendations for standardized procedures for the on-line and off-line measurement of exhaled lower respiratory nitric oxide and nasal nitric oxide in adults and children-1999. This official statement of the American Thoracic Society was adopted by the ATS Board of Directors, July 1999. Am J Respir Crit Care Med. 1999 Dec;160(6):2104-17.

36 Horváth I, Barnes PJ, Loukides S, Sterk PJ, Högman M, Olin AC, et al. A European Respiratory Society technical standard: exhaled biomarkers in lung disease. Eur Respir J. 2017 Apr;49(4):1600965. 